\title{
Cardiovascular co-medication among users of antiobesity drugs: a population-based study
}

\author{
Merethe Omdal Amundsen • Bo Engdahl • \\ Christian Berg $\cdot$ Hedvig Nordeng
}

Received: 22 December 2009/ Accepted: 9 August 2010/Published online: 29 August 2010

(C) The Author(s) 2010. This article is published with open access at Springerlink.com

\begin{abstract}
Aim The purpose of this study was to investigate to what extent patients using prescription antiobesity drugs (orlistat, sibutramine and rimonabant) used cardiovascular and antidiabetic drugs. An additional aim was to investigate whether such co-medication differed according to gender, age and amount of antiobesity drugs used. Method Data were retrieved from the Norwegian Prescription Database (NorPD). All patients who had an antiobesity drug (ATC code A08A) dispensed from a Norwegian pharmacy between January 2004 and December 2007 were included in the study. Results During the 4-year study period 83,717 patients had antiobesity drugs dispensed. One in three patients using antiobesity drugs had at least on one occasion used a cardiovascular and/or an antidiabetic drug concomitantly. A significantly higher percentage of men used antihypertensives (40.4 vs. $27.2 \%, P<0.0005$ ), lipid modifying agents (24.4 vs. $11.9 \%$, $P<0.0005)$ and drugs used in diabetes $(12.7$ vs. $6.4 \%$, $P<0.0005)$ concomitantly with antiobesity drugs when compared to women. The percentage of patients who had concomitant drug use increased markedly with age. One in four patients had antiobesity drugs dispensed only once during the period 2004-2007. Conclusion Use of
\end{abstract}

M. O. Amundsen $\cdot$ H. Nordeng $(\bowtie)$

Department of Pharmacy, School of Pharmacy,

University of Oslo, P.O. Box 1065, 0316 Blindern, Norway

e-mail: h.m.e.nordeng@farmasi.uio.no

B. Engdahl $\cdot$ H. Nordeng

Division of Mental Health, Norwegian Institute of Public Health,

P.O. Box 4404, 0403 Nydalen, Oslo, Norway

C. Berg

Division of Epidemiology, Norwegian Institute of Public Health,

P.O. Box 4404, 0403 Nydalen, Oslo, Norway cardiovascular and antidiabetic drugs among patients using antiobesity drugs was extensive, especially among men and elderly patients. Overall, there was a high degree of polypharmacy among users of antiobesity drugs. Also, many patients dispensed antiobesity drugs in amounts that indicated use less than the recommended daily dose, and many dispensed antiobesity drugs only once. When prescribing antiobesity drugs to patients the potential benefits of antiobesity drugs should be considered in relation to the patients other chronic diseases and to the total complexity of the patients drug regimen.

Keywords Antidiabetic drugs - Antiobesity drugs . Cardiovascular drugs · Co-medication · Norway · Prescription database

\section{Impact of findings on practice}

- One out of every three patients using antiobesity drugs, also use cardiovascular and/or an antidiabetic medication.

- Users of antiobesity drugs in Norway are most commonly women, and between 50 and 59 years old.

- In Norway, polypharmacy is extensive among patient using antiobesity drugs with an average of seven prescribed drugs per patient per year.

\section{Introduction}

WHO estimated in 2005 that approximately 1.6 billion adults were overweight and at least 400 million adults were obese [1]. Overweight and obesity pose a major risk for 
serious diet-related chronic diseases, including type 2-diabetes, cardiovascular diseases, hypertension and stroke [2, 3]. The health consequences range from increased risk of premature death, to serious chronic conditions that reduce the overall quality of life [2]. The metabolic and vascular benefits of even modest reductions in weight have been well described [3].

The literature on drug use among overweight and obese patients is strikingly sparse. Two studies have demonstrated that a higher percentage of obese patients use prescription drugs compared to patients of normal weight $[4,5]$. In a study with 2,300 patients in the UK, a higher percentage of obese patients used drugs affecting the cardiovascular system (36.1 vs. $20.1 \%$ ) and the endocrine system (26.0 vs. $17.9 \%)$ when compared to patients of normal weight [4]. The prescribing volume (number of defined daily doses, DDD) was also higher among obese patients [4]. In a Dutch study from 2006 they found that a higher percentage of women compared to men were prescribed cardiovascular drugs (ATC-category C) (28.8 vs. $25.2 \%$ among overweight patients and 37.8 vs. $32.1 \%$ among obese patients) [5].

An American study has shown that only $1.6 \%$ drug-eligible obese patients trying to lose weight used antiobesity drugs [6]. Having concurrent dyslipidaemia was significantly associated with a decreased likelihood of receiving a prescription antiobesity drug, and having hypertension was not associated with having an antiobesity prescription either [7].

There are two drugs approved for the treatment of obesity in Norway: orlistat (Xenical ${ }^{\circledR}$, Roche) and sibutramine (Reductil ${ }^{\circledR}$, Abbott). These drugs are indicated as adjunctive therapy within a weight management program for obese patients $(\mathrm{BMI} \geq 30$ ) or overweight patients (BMI $\geq 28 / 27$ ) if other obesity-related risk factors such as type 2-diabetes or dyslipidaemia are present [8, 9]. When compared to placebo, orlistat reduces weight by $2.9 \mathrm{~kg}$ (95\% CI $2.5-3.2 \mathrm{~kg}$ ) and sibutramine by $4.2 \mathrm{~kg}$ $(3.6-4.7 \mathrm{~kg})$ [10]. Weight loss with orlistat is also associated with a reduced incidence of diabetes and improved concentrations of total cholesterol and low density lipoprotein cholesterol (LDL-cholesterol), lowered blood pressure and improved glycemic control in patients with diabetes. Treatment with orlistat increases rates of gastrointestinal side effects and slightly lowers concentrations of high density lipoprotein cholesterol (HDL-cholesterol). Weight loss with sibutramine is associated with increased concentrations of HDL-cholesterol and lowered triglycerides-levels, but can lead to raised blood pressure and pulse rate [10]. Sibutramine has temporarily been removed from the European market due to an increased risk of serious, non-fatal cardiovascular events, such as stroke or heart attack [11].
In 2006 rimonabant Acomplia $^{\circledR}$, Sanofi-Aventis) was approved for the treatment of obesity in Norway. Compared to placebo, rimonabant reduces weight by $4.7 \mathrm{~kg}$ (4.1-5.3 kg) and improves concentrations of HDL-cholesterol and triglycerides, blood pressure and glycemic control in patients with diabetes but increases the risk of mood disorders [10, 12]. However, the drug was suspended in Europe in October 2008 as a group of endocrinologists, cardiologists and psychiatrists concluded that the benefits of the drug no longer outweighed its risks [13, 14]. The risk of psychiatric side effects was approximately twice as high in patients taking rimonabant compared to patients taking placebo.

Few pharmacoepidemiological studies on the characteristics of patients using antiobesity drugs have been conducted so far. A population-based study in Denmark showed that over $50 \%$ of the patients using antiobesity drugs were at the same time treated for type 2-diabetes, hypertension or dyslipidaemia [15]. However, 'at the same time' was in this study defined as having antiobesity and antidiabetic drugs, antihypertensives or lipid modifying agents dispensed between 1994 and 2007 regardless of whether there was an overlap with treatment with antiobesity drugs.

A population-based study from the Netherland found that diabetes mellitus and hypertension was twice as prevalent among patients starting to use antiobesity drugs when compared to overweight patients not being prescribed antiobesity drugs [16]. In addition, they found that antiobesity drugs were used for a relatively short period of time, and the majority of the patients received only a single prescription in the year following the index date.

Despite our limited knowledge on how antiobesity drugs are being used, these drugs are currently widely used. Drug sales in the global antiobesity market approached US \$2 billion in 2008 [17].

The aim of the present study was to investigate to what extent patients using prescription antiobesity drugs (orlistat, sibutramine and rimonabant) in Norway used cardiovascular and antidiabetic drugs. An additional aim was to investigate whether such co-medication differed according to gender, age and amount of antiobesity drugs used. By investigating these issues we hope to achieve an increase in the overall knowledge about patients using antiobesity drugs.

\section{Method}

\section{Data material}

Data were retrieved from the Norwegian Prescription Database (NorPD). NorPD covers the entire Norwegian 
population (4.7 million inhabitants) [18]. Since the 1 st of January 2004, the Norwegian Institute of Public Health has received monthly data on prescriptions from all Norwegian pharmacies [18]. During 2004-2007 more than 4.2 million individuals have been recorded in NorPD with at least one prescription drug dispensed from a pharmacy. NorPD contains information about all drugs prescribed (reimbursed or not) and dispensed at pharmacies to individual patients in primary care. Drugs sold over-the-counter (OTC) are not recorded. Some of the data collected are the patients' unique identification numbers (encrypted), gender and age, the prescribers' unique identification number (encrypted), the date of dispensing, drug information (e.g., package size, number of packages and ATC code) and number of DDD dispensed [18].

\section{Patients}

All patients who had an antiobesity drug (ATC code A08A) dispensed between the 1st of January 2004 and the 31st of December 2007 were included in the study. During the study period this included 3 drugs: orlistat (ATC code A08A B01), sibutramine (ATC A08A A10) and rimonabant (ATC A08AX01). Information on all other prescription drugs these patients were dispensed during the same period was also retrieved. Cardiovascular and antidiabetic drugs were defined according to the Anatomical Therapeutic Chemical (ATC) classification system and included the following subgroups: antihypertensives (ATC groups C02, C03, C07, C08 and C09), lipid modifying agents (ATC group C10) and drugs used in diabetes (ATC group A10). ATC/DDD version from January 2008 was used in this study [19].

\section{Data analysis}

One year prevalence and prevalence for the 4-year period (per 1,000 inhabitants) of antiobesity drug use were calculated. Prevalence was stratified by gender and age group ( $<10,10-19,20-29$ years etc. up to $>90$ years). The gender and age distribution was compared to the distribution of all patients included in NorPD in 2007 ( $n=3,215,584)$. We also calculated the number of times the patients had antiobesity drugs dispensed and the number of DDD they dispensed during their treatment. DDD were employed as units of measurements as prescribed daily doses were not available from the NorPD. The period of treatment was defined as the period between the first date the patient had antiobesity drugs dispensed and the last date the patient had any antiobesity drugs left according to dispensed DDD's. Daily users were defined as those using on average 1 DDD per day $( \pm 20 \%)$ during their period of treatment. Low and high consumers were defined as patients using on average less than 0.5 DDD per day and more than 1.5 DDD per day, respectively. Season variation was calculated as the average number of prescriptions dispensed each month during the study period.

Co-medication with cardiovascular and antidiabetic drugs was defined in two different ways; 'concomitant' if treatment with the cardiovascular/antidiabetic drugs and antiobesity drugs were overlapping, and 'concurrent' if the different drugs were dispensed during the same year. A more detailed description on the definition of concomitant and concurrent drug use is given by Tobi et al. [20]. The proportion of patients in the study population who had concomitant/concurrent drug use was compared with the entire NorPD population with respect to use of cardiovascular drugs and drugs used in diabetes.

Student's $t$ test was used for comparing means and $\chi^{2}$ test was used to investigate factors associated with co-medication among the patients. Large-sample significance tests for comparing two proportions were used to compare the extent of co-medication between different groups. Statistical tests were considered significant when $P<0.05$ (two-tailed). All statistical analyses were performed with the Statistical Package for Social Sciences SPSS for Windows version 16.0 (SPSS, Chicago, IL, USA).

\section{Results}

The characteristics of patients using antiobesity drugs

During the 4-year period (2004-2007) there were 83,717 patients who had antiobesity drugs dispensed in Norway; approximately 35,600 patients each year (7.8 users per 1,000 inhabitants). Orlistat was dispensed to $57.8 \%$ of the patients, sibutramine to $51.2 \%$ and rimonabant to $6.9 \%$. Overall $78.5 \%$ of the patients were women. The median age at the first dispensed antiobesity drug was 44 years for the total study population. Women were significantly younger than men (43 years for women and 46 years for men) when first dispensed an antiobesity drug $(P<0.001)$. The prevalence was highest among 50 to 59-year-olds with approximately 13 users per 1,000 inhabitants per day per year.

The patients had antiobesity drugs dispensed on average 3.5 times per year, and 5.9 times during the 4-year period. A total of $25.0 \%$ of the patients had antiobesity drugs dispensed only once. Among patients who had orlistat and rimonabant dispensed, 51.4 and $60.5 \%$, respectively, had the drugs dispensed once or twice. Among the patients who had antiobesity drugs dispensed more than once, $31.1 \%$ were defined as 'daily users' during the time they were on antiobesity drug therapy, $35.7 \%$ were defined low consumers and $2.4 \%$ were high consumers. High consumers were most frequently men (3.6 vs. $2.1 \%, P<0.001)$. Age 
did not have a significant impact on the consumption of antiobesity drugs.

There was a marked season variation in use of the three antiobesity drugs with the highest dispensing rate in June (in average a total of 12,058 antiobesity prescriptions per year) and lowest in February (in average 9,146 per year).

The patients had prescriptions dispensed for an average of seven different drugs (different ATC 5th level codes, range 1-64 drugs) prescribed by in average three different physicians per year. The range of prescribing physicians was 1-57. Women had slightly, but significantly more drugs prescribed (4.5 vs. 4.0 drugs, $P<0.001)$ and from more prescribers (in average 2.8 vs. $2.5, P<0.001$ ) yearly.

The percentage of individuals who had drugs dispensed that belong to the different ATC main groups was in 2007 over $40 \%$ higher among patients using antiobesity drugs when compared to the general population in NorPD for some ATC groups [ATC groups $\mathrm{N}$-nervous system (53 vs. $37 \%$ ), $\mathrm{M}$-musculoskeletal system (47 vs. $28 \%$ ), Ccardiovascular system (39 vs. 27\%), G-genital urinary system and sex hormones (30 vs. 21\%) and $\mathrm{H}-$ systemic hormonal preparations excluding sex hormones and insulin (18 vs. $11 \%)]$.
Use of cardiovascular and antidiabetic co-medication

There was considerable co-medication among the patients who had antiobesity drugs dispensed during 2004-2007 (Table 1). A higher percentage of men had concomitant use of antiobesity drugs and antihypertensives (40.4 vs. $27.2 \%, P<0.0005)$, lipid modifying drugs (24.4 vs. $11.9 \%$, $P<0.0005)$ and drug used in diabetes $(12.7$ vs. $6.4 \%$, $P<0.0005)$ when compared to women. The percentage that had concomitant drug use increased markedly with age. Patients who had antiobesity drugs dispensed only once used other prescription drugs concomitantly less frequently than patients who had the drugs dispensed more than once. There were small, but significant differences in the extent of concomitant drug use between the different DDD/daygroups (Table 1).

A significantly higher percentage of the study population had cardiovascular and antidiabetic drugs dispensed in 2007 when compared to the general NorPD population (Table 2). The difference in percentages decreased with age. The predominance of men was higher among patients using antiobesity drugs when compared to the patients in NorPD.

Table 1 Concomitant use of cardiovascular and antidiabetic drugs among patients who had antiobesity drugs dispensed during 2004-2007

\begin{tabular}{|c|c|c|c|c|c|c|c|c|c|c|}
\hline \multirow[t]{2}{*}{ Group } & \multicolumn{2}{|c|}{$\begin{array}{l}\text { Cardiovascular } \\
\text { drugs }^{\text {a }}\end{array}$} & \multicolumn{2}{|c|}{ Antihypertensives ${ }^{\mathrm{b}}$} & \multicolumn{2}{|c|}{$\begin{array}{l}\text { Lipid modifying } \\
\text { agents }^{\mathrm{c}}\end{array}$} & \multicolumn{2}{|c|}{$\begin{array}{l}\text { Drugs used } \\
\text { in diabetes }\end{array}$} & \multicolumn{2}{|c|}{$\begin{array}{l}\text { Total concomitant } \\
\text { drug use }\end{array}$} \\
\hline & $n$ & $\%$ & $n$ & $\%$ & $n$ & $\%$ & $n$ & $\%$ & $n$ & $\%$ \\
\hline Total study population & 28,445 & 34.0 & 25,128 & 30.0 & 12,235 & 14.6 & 6,520 & 7.8 & 69,496 & 83.0 \\
\hline \multicolumn{11}{|l|}{ Gender } \\
\hline Men & 8,212 & 45.7 & 7,261 & 40.4 & 4,386 & 24.4 & 2,286 & 12.7 & 14,270 & 79.4 \\
\hline Women & 20,233 & 30.8 & 17,867 & 27.2 & 7,849 & 11.9 & 4,234 & 6.4 & 55,226 & 84.0 \\
\hline \multicolumn{11}{|l|}{ Age (years) } \\
\hline $0-29$ & 611 & 4.7 & 517 & 4.0 & 126 & 1.0 & 413 & 3.2 & 9,682 & 74.8 \\
\hline $30-59$ & 19,283 & 32.7 & 16,862 & 28.6 & 7,666 & 13.0 & 4,364 & 7.4 & 48,590 & 82.4 \\
\hline $60-99$ & 8,551 & 72.6 & 7,749 & 65.8 & 4,443 & 37.7 & 1,743 & 14.8 & 11,224 & 95.3 \\
\hline \multicolumn{11}{|c|}{ No. of prescriptions of antiobesity drugs } \\
\hline 1 & 5,896 & 28.2 & 5,111 & 24.5 & 2,569 & 12.3 & 1,299 & 6.2 & 15,039 & 72.0 \\
\hline$>1$ & 22,549 & 35.9 & 20,017 & 31.9 & 9,666 & 15.4 & 5,221 & 8.3 & 54,457 & 86.7 \\
\hline \multicolumn{11}{|c|}{ Amount of antiobesity drugs dispensed (DDD/year) } \\
\hline$<290$ & 14,520 & 37.8 & 12,929 & 33.7 & 6,182 & 16.1 & 3,195 & 8.3 & 34,222 & 89.2 \\
\hline $290-360$ & 6,382 & 32.7 & 5,631 & 28.8 & 2,787 & 14.3 & 1,601 & 8.2 & 16,097 & 82.4 \\
\hline$>360$ & 1,647 & 33.6 & 1,457 & 29.7 & 697 & 14.2 & 425 & 8.7 & 4,138 & 84.3 \\
\hline
\end{tabular}

a ATC group C

b ATC group C02, C03, C07, C08 and C09

c ATC group C10

d ATC group A10

e Any drug except antiobesity drugs 
Table 2 Use of cardiovascular and antidiabetic drugs among patients who had antiobesity drugs dispensed $(n=36,772)$ and among the general population $(n=3,215,584)$ in NorPD in 2007

\begin{tabular}{|c|c|c|c|c|c|c|c|c|}
\hline \multirow[t]{2}{*}{ Group } & \multicolumn{2}{|c|}{ Cardiovascular drugs ${ }^{\mathrm{a}}$} & \multicolumn{2}{|c|}{ Antihypertensives ${ }^{\mathrm{b}}$} & \multicolumn{2}{|c|}{ Lipid modifying agents $^{c}$} & \multicolumn{2}{|c|}{ Drugs used in diabetes ${ }^{\mathrm{d}}$} \\
\hline & SP & NorPD & SP & NorPD & SP & NorPD & SP & NorPD \\
\hline Total use & 36.7 & 27.5 & 33.4 & 22.5 & 17.0 & 12.4 & 9.4 & 4.1 \\
\hline \multicolumn{9}{|c|}{ Use according to gender } \\
\hline Men & 48.7 & 29.2 & 44.7 & 23.8 & 28.3 & 14.7 & 15.1 & 5.0 \\
\hline Women & 33.6 & 26.1 & 30.5 & 21.4 & 14.1 & 10.5 & 7.9 & 3.4 \\
\hline \multicolumn{9}{|c|}{ Use according to age (years) } \\
\hline $0-29$ & 4.6 & 2.0 & 4.0 & 0.7 & 0.8 & 0.2 & 3.9 & 0.8 \\
\hline $30-59$ & 32.1 & 20.5 & 28.5 & 15.0 & 13.0 & 8.3 & 8.1 & 3.4 \\
\hline 60-99 & 73.7 & 65.7 & 69.3 & 57.6 & 41.9 & 32.0 & 17.6 & 8.8 \\
\hline
\end{tabular}

Numbers given in percents

All differences in proportions $(\%)$ between SP and NorPD are statistic significant $(P<0.0005)$

$S P$ study population, NorPD Norwegian Prescription Database

a ATC group C

b ATC group C02, C03, C07, C08 and C09

c ATC group $\mathrm{C} 10$

d ATC group A10

\section{Discussion}

The use of antiobesity drugs differed both according to gender and age. Difference in the occurrence of obesity between men and women cannot alone explain the fact that four out of five patients who had antiobesity drugs dispensed were women. The percentage of obese individuals is $20 \%$ among Norwegian inhabitants under the age of 60 irrespective of gender [21]. Factors more likely to explain the higher frequency of female antiobesity drug users may be that women tend to be more concerned about their health and visit their GP more often than men [22, 23]. Women are also far more likely to seek and accept weight management support from their family doctor [23].

Most patients were middle-aged (30-69 years). This can be explained by the fact that the percentage of the Norwegian population being obese is higher among adults than among children and youths [21]. Younger patients do not use drugs to the same extent as older patients either [18], and consequently, their threshold for using drugs to lose weight may be higher. Antiobesity drugs are also relatively expensive (daily cost range from 1.75 to $3.10 €$ ) and are not reimbursed in Norway. This may also be an important explanation for the limited use; only $1 \%$ of the patients in NorPD used antiobesity drugs.

This study shows that approximately one out of three patients who had antiobesity drugs dispensed also had cardiovascular drugs or antidiabetic drugs dispensed, indicating a high degree of metabolic and cardiovascular co-morbidity. This is almost identical to a recently published study from the Netherlands where $33 \%$ of patients starting antiobesity drugs reported using cardiovascular drugs [16]. Both these two studies demonstrate the magnitude of cardiovascular diseases among these patients. Patients with cardiovascular co-morbidity may especially benefit from reducing weight [3]. These patients may even be prescribed antiobesity drugs as part of treatment for their cardiovascular disease. We find it therefore interesting that men had a higher degree of co-medication with cardiovascular and antidiabetic drugs compared to women, and speculate that this can be due to a difference in the frequency of underlying co-morbidity.

In addition to cardiovascular co-morbidity, our study also demonstrates the magnitude of polypharmacy among patients who had antiobesity drugs dispensed. Of importance, the patients in our study had in average seven different prescription drugs dispensed yearly. Several studies have previously documented the many challenges related to polypharmacy [24-28]. Adherence decreases with an increasingly complex drug regimen [24, 27]. In addition, the risk of drug interactions and adverse effects increases with an increasing number of prescribed drugs [26]. A recently published study on polypharmacy among diabetic patients with cardiovascular co-morbidity showed that many patients had poor adherence and little knowledge about why the drugs were prescribed [28]. Our results indicate that adherence or consumption of antiobesity drugs is suboptimal as three out of five patients had a dispensing pattern indicating use of doses less than the defined daily dose recommended. Also interestingly, many patients had antiobesity drugs dispensed only once or twice during 2004-2007. This applies especially for rimonabant 
and orlistat. Rimonabant was marketed in Norway in September 2006, which may explain limited use of this drug. The high prevalence of side effects associated with the use of rimonabant, including depression, anxiety and irritability, may also be an explanation. Gastrointestinal side effects may lead to early termination of treatment with orlistat. Therapy with orlistat should also be stopped after 12 weeks if the patient has been unable to lose at least $5 \%$ of the body weight since the start of treatment [8]. Lack of information from the prescribing physician can also lead to short-term therapy [29]. The frequent side effects and the relatively high drug prices may also explain why almost one out of three patients who had antiobesity drugs dispensed more than once were low consumers or had a discontinuous use of the medicine. In addition, lack of effectiveness or perceived lack of effectiveness has been shown to be an important cause of drug discontinuation [24]. Antiobesity drugs have in average a weight loss of $3-5 \mathrm{~kg}$ which some patients may perceive as a marginal effect $[8,9,12]$.

\section{Limitations}

Data from NorPD does not provide information on variables like BMI and the indication for drug use. These variables would have been valuable for estimating to what extent the patients are treated in accordance with the approved indications. The study is also based on drug dispensing information. We do not know if the drugs were actually taken by the patients and in which degree they used the antiobesity drugs daily. Also the DDDs used in our calculations were not necessarily the prescribed doses or the doses actually taken by the patients. Our results should be interpreted with these limitations in mind.

\section{Conclusion}

There was a high degree of polypharmacy among users of antiobesity drugs; in average the patients had seven different drugs dispensed by three different physicians yearly. More specifically, one out of three patients who had antiobesity drugs dispensed used cardiovascular drugs or antidiabetic drugs. Such co-medication was especially extensive among men and elderly patients. This indicates a high degree of cardiovascular and metabolic co-morbidity among these patients. Patients may not benefit optimal of the antiobesity drug as one out of three had doses dispensed that indicate use of doses less than the recommended daily dose. Also, as one out of four patients had antiobesity drugs dispensed only once adverse effects, high drug cost and/or perceived lack of effectiveness may be common. When prescribing antiobesity drugs to patients the potential benefits of pharmacologically induced weight reduction should be considered in relation to the patients other chronic diseases and to the total complexity of the patients drug regimen.

Acknowledgment We would like to thank 'The Foundation for Promotion of Norwegian Pharmacies'.

Funding This work was funded by 'The Foundation for Promotion of Norwegian Pharmacies'.

\section{Conflicts of interest None.}

Open Access This article is distributed under the terms of the Creative Commons Attribution Noncommercial License which permits any noncommercial use, distribution, and reproduction in any medium, provided the original author(s) and source are credited.

\section{References}

1. WHO. Obesity and overweight. What are overweight and obesity? http://www.who.int/mediacentre/factsheets/fs311/en/index. html; 2006. Accessed 13 June 2010.

2. WHO. Obesity and overweight. http://www.who.int/hpr/NPH/ docs/gs_obesity.pdf; 2003. Accessed 13 June 2010.

3. Haslam D, Sattar N, Lean M. ABC of obesity. Obesity-time to wake up. Br Med J. 2006;333:640-2.

4. Counterweight Project Team. The impact of obesity on drug prescribing in primary care. Br J Gen Pract. 2005;55:743-9.

5. van Dijk L, Otters HB, Schuit AJ. Moderately overweight and obese patients in general practice: a population based survey. BMC Fam Pract. 2006;7:43.

6. Pokras SM, Klingman D, Annunziata K, Chapnick J, Tierce J. Utilization and patient experience with obesity prescriptions in the US. Pharmacoepidemiol Drug Saf. 2008;17(Suppl 1):S142 (abstract 324).

7. Pokras SM, Klingman D, Tierce JC. Factors associated with prescription of obesity medications in the US. Pharmacoepidemiol Drug Saf. 2008;17(Suppl 1):S143 (abstract 326).

8. The Norwegian Medicines Agency. SPC-orlistat. http://www. legemiddelverket.no/custom/Preparatsok/prepSearch__ 80333. aspx? ? earchID=0a6afb93-7531-4c58-b8b5-586062d5c4e8. Accessed 13 June 2010.

9. The Norwegian Medicines Agency. SPC-reductil. http://www. legemiddelverket.no/custom/Preparatsok/prepSearch__ 80333. aspx?SearchID=a730bc6a-4b18-4e5b-9d81-a00da5aba98e. Accessed 13 June 2010.

10. Rucker D, Padwal R, Li SK, Lau DC. Long term pharmacotherapy for obesity and overweight: updated meta-analysis. $\mathrm{Br}$ Med J. 2007;335:1194-9.

11. EMEA. European Medicines Agency recommends suspension of marketing authorizations for sibutramine. http://www.ema.europa. eu/pdfs/human/referral/sibutramine/3940810en.pdf; 2010. Accessed 13 July 2010.

12. EMEA. SPC-Acomplia. http://www.ema.europa.eu/humandocs/ PDFs/EPAR/acomplia/H-666-PI-da.pdf. Accessed 13 June 2010.

13. EMEA. Press release. The European Medicines Agency recommends suspension of the marketing authorisation of Acomplia. http://www.emea.europa.eu/humandocs/PDFs/EPAR/acomplia/ 53777708en.pdf; 2008. Accessed 13 June 2010.

14. EMEA. Questions and answers on the recommendation to suspend the marketing authorisation of Acomplia (rimonabant). 
http://www.emea.europa.eu/humandocs/PDFs/EPAR/acomplia/ 53715308en.pdf; 2008. Accessed 13 June 2010.

15. Lægemiddelstyrelsen. Brug af receptpligtige slankelægemidler 2003-2007 [Use of prescription antiobesity drugs]. http://www. laegemiddelstyrelsen.dk/statistik/forbrugsanalyser/slankemidler/ slankemidler_notat2.asp; 2008. Accessed 13 June 2010 (in Danish)

16. Willemen MJ, Mantel-Teeuwisse AK, Straus SM, Leufkens HG, Egberts AC, Sturkenboom MC. Cardiovascular and psychiatric risk profile and patterns of use in patients starting anti-obesity drugs. Pharmacoepidemiol Drug Saf. 2009;18:631-8.

17. Reuter. Learn about the anti-obesity treatments markets: analysis \& forecasts 2009-2024. http://www.reuters.com/article/pressRelease/ idUS139205+30-Mar-2009+BW20090330; 2009. Accessed 13 June 2010.

18. Rønning M, Berg CL, Furu K, Litleskare I, Sakshaug S, Strøm H. The Norwegian Prescription Database 2004-2007. Oslo: The Norwegian Institute of Public Health; 2008. ISBN:978-82-8082253-6.

19. WHO Collaborating Centre for Drug Statistics Methodology. Guidelines for ATC classification and DDD assignment 2008, 11th edn. Oslo: The Norwegian Institute of Public Health; 2007. ISBN:978-82-8082-369-4.

20. Tobi H, Faber A, van den Berg PB, Drane JW, den Berg LT. Studying co-medication patterns: the impact of definitions. Pharmacoepidemiol Drug Saf. 2007;16:405-11.

21. Ulset E, Undheim R, Malterud K. Has the obesity epidemic reached Norway? Tidsskr Nor Lægeforen. 2007;127:34-7 (in Norwegian).

22. Ministry of Health and Care Services. NOU 1999: 13. Kvinners helse i Norge. Kapittel 1.9: Kjønnsperspektiv på helsetjenestetilbud og -forbruk [Womens health in Norway. Chapter 1.9: The gender perspective on health services and health services consumption] (in Norwegian).

23. Counterweight Project Team. Evaluation of the counterweight programme for obesity management in primary care: a starting point for continuous improvement. Br J Gen Pract. 2008;58: 548-54.

24. Elliott RA, Ross-Degnan D, Adams AS, Safran DG, Soumerai SB. Strategies for coping in a complex world: adherence among older adults with chronic illness. J Gen Intern Med. 2007;22: 805-10.

25. Grant RW, Devita NG, Singer DE, Meigs JB. Polypharmacy and medication adherence in patients with type 2 diabetes. Diabetes Care. 2003;26:1408-12.

26. Volpe M, Chin D, Paneni F. The challenge of polypharmacy in cardiovascular medicine. Fundam Clin Pharmacol. 2010;24:9-17.

27. Benner JS, Chapman RH, Petrilla AA, Tang SS, Rosenberg N, Schwartz JS. Association between prescription burden and medication adherence in patients initiating antihypertensive and lipid-lowering therapy. Am J Health Syst Pharm. 2009;66: 1471-7.

28. Harder S, Saal K, Blauth E, Beyer M, Gerlach FM. Appropriateness and surveillance of medication in a cohort of diabetic patients on polypharmacy. Int J Clin Pharmacol Ther. 2009;47: 104-10.

29. Linné Y, Rooth P, Rössner S. Success rate of orlistat in primarycare practice is limited by failure to follow prescribing recommendations: the referral letter content vs. clinical reality. Int J Obes Relat Metab Disord. 2003;27:1434-5. 